\title{
Editorial
}

\section{A NEW DISCIPLINE: WASTE PREVENTION MANAGEMENT}

We live in challenging times: climate change, with vast fires, flooding, droughts, hurricanes, coronavirus pandemics, difficult political situations and now also limited resources resulting in reduced production in the construction sector and car industry. Economies need more raw materials for their steadily increasing production. Wood, steel, plastics, and other materials are becoming scarce. Prices for soya, palm oil, wood, sand, and steel have increased significantly due to reduced availability on the world market. This lack has been caused by a series of reasons, such as increased production "after" coronavirus, worldwide competition, supply chains, and availability of natural resources. This situation highlights how vulnerable industry is, and that the times of abundant availability are over. The situation of the rare earth elements Gallium (Semiconductors), Germanium (Optical Fibres), Indium (flat screens) and Hafnium (Superalloys), which are becoming depleted and are not replaceable (https://goldengates.de/de/ratgeber/rohstoffknappheit-2021/) is particularly critical.

It is time to do more with regards to resource saving and substituting rare materials, otherwise our quality of life will change significantly. I think we are approaching a tipping point. Although we have known about the endlessness of resources for a long time, to date very little action has been taken.

\section{Circular Economy}

A popular opinion maintains that the application of Circular Economy (CE) and other approaches such as Zero Waste and Cradle to Cradle solves all waste management problems. We all have seen the closed circle that graphically describes the CE. People may get the impression that material use is unlimited, producing little or no residues for disposal. I do not intend to question the CE, but it is essential to look at what is actually behind it.

Until now, the CE has not heralded the necessary breakthrough in waste reduction: waste production globally has not changed much (Simon and Holm, 2018). The worldwide average waste production amounts to $1.2 \mathrm{~kg} / \mathrm{Pers} . / \mathrm{d}$ and as predicted by the World Bank - will reach $1.42 \mathrm{~kg} /$ Pers./d in 2025. Even in Germany, with relatively high recycling rates, waste production remains almost constant. Statistics report high recycling rates for different countries, and Germany often sees itself as the waste recycling champion. However, on looking more closely at these rates, how the data are collected and which measures count as recycling, the situation is rather different. In Germany for example, separately collected packaging waste that enters a recycling plant counts as recycled. I would estimate that $20 \%-30 \%$ of the material is not recyclable (think of particle sizes $<40 \mathrm{~mm}$ ); these residues are mainly thermally utilized. It should be taken into account that, in general, municipal waste (MSW) incinerators have an energy efficiency for electricity production of $<20 \%$.

Parts of used electronics (most no longer functional), clothing, separately collected plastic waste and paper are shipped to Africa, Asia, and other non-European areas and enter statistics as recycled. I am very skeptical as to the recycling efficiency for the different materials in the receiving countries, without any control (see also Bartl, 2014; 2020).

\section{Waste statistics}

What should we look at when scrutinizing waste recycling statistics? In Germany for example, official material recycling rates for separately collected glass (2016: 85.5\%), paper (2018: around $76 \%$ ) and plastic (2017: 46.7 $\%)$ - https://www. umweltbundesamt.de - are relatively high, but one has to take into account separate waste material collection rates between 50\%-70\% (htpps://www.bmu.de). For plastic, actual material recycling lies between $23 \%$ and $32 \%$. Reutilization cycles for paper and plastic are limited to 5-7 times, i.e., for new - mainly low quality- paper production, approx. $28 \%$ virgin material has to be added (www. altpapier.ch).

It is a widespread opinion that metals can be recycled endlessly. However, the presence of numerous alloys will modify the original metal quality, which limits the recycling of certain metals. Trace elements that improve metal characteristics can often not be recovered during thermochemical reprocessing because they stay in the slag or remain in the metal. Reck et al. (2012) presented the results of Markov chain modelling, "which shows that a unit of the common metals iron, copper, or nickel is only reused two or three times before being lost gainsaying metals being repeatedly recyclable" the notion of a consequent approach can save certain industries from timely collapsing due to a lack of resources".

In the majority of cases, recycling is actually a down-cycling of resources, and statistical data of material recycling rates do not indicate the quality of the recycled product. The products from material recycling are frequently of a low value, although improvements may be gained by means of more detailed separation, such as into different types of plastics. Material recycling rates for electrical and electronic waste are pretty low. Following the recovery of compounds with high values such as gold, copper and oth- 
er metals, the plastic parts are often energetically used in metal smelters, cement kilns, and waste incinerators. Statistics frequently fail to distinguish between energy and material recovery.

I should also like to discuss another aspect: the general opinion that recycling only makes sense if profitable. This opinion is one of the reasons why large amounts of recycled plastic are thermally treated. We need a new approach and take natural resource savings as a benchmark; costs are substantial, but they should not control recycling. This approach is comparable with climate change, where all necessary interventions must be undertaken.

\section{Waste prevention}

Why do I mention all this? Although efficient separate collection and mechanical separation techniques are available, the material recycling rates and quality of products are generally relatively low. Recycling as practiced today has reached its limits, and therefore, other forms of waste avoidance should be fostered to save more resources. This approach is vital for humankind to avoid the onset of a significant economic recession with increasing global pollution.

Waste prevention "... takes place before products or materials are identified or recognised as waste" (OECD, 2000). Waste prevention is part of waste minimization. The latter encompasses prevention and or reduction of waste at the source, improving the quality of the generated waste, such as lowering the hazardous element, and encouraging reuse, recycling and recovery.

When waste recycling is carried out, this implies that waste has been produced and requires some form of treatment. In the case of avoidance, no waste is produced (primary avoidance).

Recycling activities should be validated, with a particular focus on waste avoidance (i.e. material avoidance, MA, = resource saving). As a consequence, we should validate recycling measures by calculating the number of saved resources. The same should be applied to refund systems.

$W A \%=M A \%=M \%-\frac{M \%}{n}$

WA: avoided waste (\%); MA: avoided material (\%); M: original material $(=100 \%)$; : number of reuses and recycling loops,

when $\mathrm{n}=1$, avoidance $=0$

The degree of waste avoidance can be calculated using equation 1: e.g. using a cup eight times means that the material saving rate is $87.5 \%$ compared to single use cups.

We need to bear in mind that all recycled materials will ultimately become waste destined for disposal (Cossu et al, 2020; Matasci et al., 2021). According to the Lavoisier law, no materials are lost, but are only transformed. According to the second law of thermodynamics, entropy increases with each utilization and recycling step; actually, I set entropy up with diffusive pollution i.e. producing non-recoverable waste.

In the official WM hierarchy, waste avoidance assumes the highest priority. Numerous regulations to this regard have already been issued, including mainly recommendations with general targets.

However, to foster waste avoidance, regulations, tax- es, and raising awareness amongst the private, public and commercial sectors is necessary: cleaner production, material saving and reuse, refund and leasing systems, change of habits, digitalization, and development of products that are easier to recycle. The necessary measures are known to us all, but need to be implemented on a large scale on a routine basis. Many technical, social, economic and logistical aspects need to be taken into account, together with their effects on emissions, used resources and consumption of energy. The use of these tools becomes rather complex due to their frequently interrelated nature. Life cycle assessment (LCA) may help to validate these processes and measures to a certain extent, although some modifications may be required as a significant consideration of resource consumption. A new tailormade model should be developed for waste recycling and prevention to clarify their relationships and provide transparency. Responsible and effective waste minimization concepts can accordingly be developed on this basis and achieve individual measures.

Worldwide, numerous systems, concepts and activities of waste avoidance are already in place (Umweltbundesamt, Germany, https://www.uba.de/uba-info-medien/4043. html). An essential goal of recycling in several countries is the diversion of waste from landfills (Zero Waste Landfilling - Zaman et al., 2013), although new priorities should be identified and consideration given to the fact that a sink for the final sustainable deposit of residues from CE are likely to be required (Cossu and Stegmann, 2019; Cossu et al., 2020).

\section{Used products back to producer and extended pro- ducer responsibility (EPR)}

Avoidance and recycling concepts for all end-use products such as electrical and electronic devices, textiles, furniture, plastic, and metal household products should be further developed.

The author supports a waste avoidance strategy, where "all" used products that the owner wishes to dispose of should be returned to the producer to reuse the entire product, parts or materials. For this purpose, factories should implement new product lines for the processing of used products into "recycled products" (exchange products). For materials that the producer cannot sensibly recycle as a second option, external recycling should be considered. The remaining non-useable product residues may end up as energy sources in MSW incinerators or industrial plants; alternatively, these residues will need to be safely landfilled. The producer must also assume responsibility for the remaining residues at their final destination.

Today, in most cases, the manufacturing industry uses third-party companies to recycle materials from their discarded products, e.g., cars. By these means, the producer is not obliged to accept responsibility for their products once they become waste. It is fundamental therefore that the producer be directly encharged with the task of recycling their used products to ensure that the company has an invested interest in saving resources and designing and manufacturing their products to fulfil the established recycling targets. Accordingly, only products complying with 
the required recycling/reuse targets and identifying the final destination of non-useable residues would be able to enter the market.

The Government should be called upon to emanate regulations and - dependent on the product group - reuse and recycling goals. To a certain extent, similar prescriptions exist for material recycling for cars, electrical and electronic products (WEEE directive) and perhaps others, but are currently lacking for product or product parts reuse and recycling. The EU should amend their regulations to comprise resource minimization of "all" products. Only the implementation of a targeted approach would save certain industries from an untimely collapse due to lack of resources.

\section{How can this concept be implemented?}

Companies often claim that their products are recycled, although the amount of product and/or material recovery is relatively low. A recycling logo on a product may be misleading because it does not inform us as to the extent and quality of recycled materials.

To provide for a greater transparency over material avoidance, I propose the introduction of the Product-Material-Avoidance Index (PMAI). The EU-Regulation 2010/30/ EU has introduced an energy label on electrical household products that shows qualitatively electrical efficacy for household devices (i.e. tumble dryers). By further developing such a label to document material and product parts avoidance rates, companies would need to ensure the reuse and recycling of their products. The Product-Material-Avoidance Index, PMAI provides details relating to reduction of use of virgin materials and substitution of product parts. The PMAI would relate to a specific product line, such as computers or refrigerators.

Actual material avoidance rates should be calculated by considering the number of reuses (equation 1). When products or parts of these consist of recycled components (e.g. a pump in a washing machine), the manufacturer should determine the percentage of avoided product parts. Different green color intensities distinguish between various product components (e.g., machine parts, electronic devices, casing), reused or recycled. The length of the bar shows recovery percentages for each category (Figure 1).

But how can the quality of the recycled materials be described? As a first approach, the author proposes three quality categories: up-cycling, recycling and down-cycling. These categories are related to different intensities of the blue color. The number of recycled materials in the three types is marked as a percentage of the total material used. This approach can be further detailed for the different kinds of materials as copper, plastic, etc. Red indicates there is no material avoidance i.e., single-use products.

If a producer claims that the detergent bottle consists of $100 \%$ recycled plastic, the limited reuse potential of plastic material - let's say seven times - reduces the actual material avoidance rate to $86 \%$ (equation 1 ), i.e. the green bar becomes a bit shorter. The label on a refrigerator may indicate that the casing consists of recycled material (steel) (yellow bar up to $90 \%$ ) and if - let's assume - the electrical pump is reused once more, the green bar extends to $50 \%$.
We are well aware that the problem lies in the details, and a similar system should probably start first with home utilities using a pragmatic, not over-detailed approach. This concept should be further developed and tested for practical application - standardization of the procedure using a model is vital.

\section{Social impact}

The options presented here aimed at increasing both product and material avoidance and, at the same time, waste production, are mainly of a technical and organizational nature. The implementation of this or similar concepts implies an inherent need for acceptance by and support from society, with politics being called upon to implement the regulatory frame for the private, industrial and commercial sectors. New waste avoidance concepts will result in fewer single-use products, less fast fashion, more second-hand products, and more recyclable-friendly designs. Subsequent to the required modification of production processes, job profiles may change. Since there are no visible short-term benefits but rather potential disadvantages for society, it is essential to convince people of the necessity of such a new concept.

Why should people buy products made partly from reused materials and product parts? First of all, legislators will establish a framework implicating the reuse of materials and mechanical and electrical components for each product line (e.g. washing machine) so that all competitors produce under the same conditions. In buying secondary products, incentives may be represented by lower prices with the same guarantee.

Companies' "green" image will become more and more important in achieving better sales performance and higher ratings on the stock market (https://youmatter.world/en/responsible-companies-perform-better-on-the-stock-market/). A recent trend highlights how more people are investing in companies that care about the environment, producing "green" technologies and saving energy and material resources.

The main challenges for producers will lie in the design and production of products using a minimal material and energy input and the reintegration of the returned used products in their production processes. Digitalization, artificial intelligence and robots may significantly support and innovate the necessary actions. New jobs will consequently be created; the unfailing Yin (阴) and the Yang (阳).

A recent example may be observed in the presentation of a BMW concept car "iVision Circular", which the producer claims consists of $100 \%$ recycled and recyclable materials. This study shows that, on a general level, this can be achieved, although BMW claims that such a car will not be available on the market before 2040 (Hamburger Abendblatt 18.9.2021). Hopefully, in the meantime, more and more parts will be substituted by recycled and recyclable materials. Increasing pressure to foster this will need to be applied by the public, the scientific field and politics.

The provision of education and information are fundamental, with all educational institutions playing a highly important role of responsibility. Numerous activities are already in the pipeline, starting from Kindergarten, where 


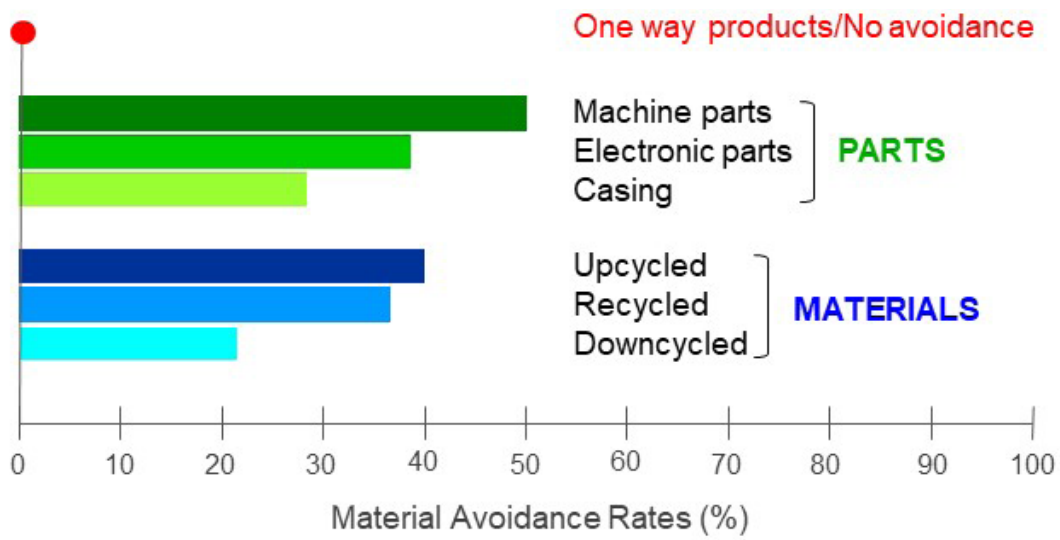

FIGURE 1: Proposal for a product label indicating the quantity and quality of avoided material used. Material avoidance rates could be calculated according to equation (1).

kids learn by playing to preserve our environment (de Feo et al., 2019). More compulsory courses on environment and sustainability should be scheduled in all disciplines taught in schools and universities as a kind of "General Studies" (Stegmann, 2018).

As has become apparent during the Coronavirus crisis, the media play a role of the utmost importance, with a wide range of media constantly presenting scientifically correct information. An identical approach should also be applied to foster waste avoidance.

\section{Conclusions}

A number of individual and commercial recycling initiatives have already been implemented: second-hand shops have become more popular on the internet; we see more detailed collections of used materials and products. Waste avoidance includes the use of less packaging and prohibiting plastic materials and products. Other initiatives include car-sharing, increased use of bicycles, opposing fast fashion. In addition, many private organizations are actively fighting for global change. These "germ cells" are essential to spread and actively support material and waste avoidance concepts.

The author keenly promotes of an intensified waste minimization by proposing practical ways and procedures to achieve increased waste prevention. Together with the stakeholders, the scientific community needs to develop new ideas and further develop waste avoidance concepts in theory and practice. Material and waste prevention should be viewed as a new scientific discipline referred to as "Resource Prevention Management" - borne by a great variety of technical and social disciplines requiring close cooperation with industry. Bartl, 2020 provides a graph illustrating a high publication rate of scientific papers on CE with increasing tendency but very low constant publications on waste prevention. This neglected discipline should encourage us to perform more targeted research in the field and adequate funding should be made available.

In the future, major cultural and social changes should be expected. There will be less food waste as more people tend to eat outside the house or to order food deliveries.
Due to digitalization, there will be less paper consumption. The increasing use of robots may open up new production processes and resource recovery procedures. More products will be purchased online, and there will be a tendency towards product leasing and home offices. All these aspects should be investigated in detail in the new scientific discipline of Resource Prevention Management.

Rainer Stegmann

Hamburg University of Technology, Hamburg, Germany stegmann@tuhh.de

\section{REFERENCES}

Bartl, A., (2014). Moving from recycling to waste prevention: a review of barriers and enables Waste Management \& Research Vol. 32(9), doi:10.1177/0734242X14541986

Bartl, A., (2020). The circular economy package of the European Union: are new paths being taken or is it an old story? Detritus (12), 12-17. doi: 10.31025/2611-4135/2020.13991

Cossu, R., Grossule, V., Lavagnolo, M. C. (2020). What about residues from circular economy and role of landfilling? Detritus, (9), 1-3. doi:10.31025/2611-4135/2020.13920

Cossu, R., Stegmann, R. (2019). Solid waste Landfilling, Concepts, Processes, Technologies, Elsevier Publisher, ISBN: 9780128183366

De Feo, G., Faiella, F. (2019). Waste management and education: from kindergarten to higher education, Proceedings Sardinia 2019, CISA Publisher, ISBN: 9788862650144

Matasci, C., Gauch, M., \& Boeni, H. (2021). How to increase circularity in the Swiss economy? Detritus (14), 25-31. doi: 10.31025/2611$4135 / 2021.14057$

OECD, (2000). Strategic waste prevention- Working Party on Pollution Prevention and Control Environment directorate environment policy committee. Reference Manual, ENV/ EPOC/ PPC(2000)5/FINAL . https://www.oecd.org/officialdocuments/publicdisplaydocumentpdf $/$ ?doclanguage $=$ en $\&$ cote $=e n v /$ epoc $/ p p c(2000) 5 /$ final (visited on the 20.09.2021)

Reck, B.K., and Graedel, T.E. (2012). Challenges in Metal Recycling Science 337, 690 doi:10.1126/science. 1217501

Simon, F.-G., and Holm, O. (2018). Resources from recycling and urban mining: limits and prospects. Detritus, (2), 24. doi:10.31025/26114135/2018.13665

Stegmann, R., (2018). Thinking from the End, 7th International Symposium on Energy from Biomass and Waste, VENICE 2018, CISA Publisher, Padova. ISBN: 9788862650137

Zaman, A.U., Lehman, S. (2013). The "zero waste index": a performance measurement tool for waste management systems in a "zero waste city", Journal of Cleaner Production, 50, 123- 132 doi:10.1016/j.jclepro.2012.11.041 